\title{
Structural and socio-psychological influences on adolescents' educational aspirations and subsequent academic achievement
}

\author{
Catherine Rothon - Muna Arephin • \\ Emily Klineberg • Vicky Cattell • \\ Stephen Stansfeld
}

Received: 11 August 2009 / Accepted: 24 June 2010 / Published online: 20 August 2010

(C) The Author(s) 2010. This article is published with open access at Springerlink.com

\begin{abstract}
Previous literature indicates that educational aspirations are an important predictor of achievement at school and beyond. This paper examines the factors that are associated with high educational aspirations. It also looks at the relationship between aspirations and achievement at the General Certificate of Secondary Education in a deprived area of London. The results show that educational aspirations are associated with individual characteristics. Girls were more likely than boys to express a wish to remain in education beyond the age of 16. For the most academic route post-16, there were substantial ethnic differences, with minority ethnic groups generally being more likely to state a desire to follow this path. Students who were eligible for free school meals tended to have lower aspirations. Socio-psychological variables were also shown to be of importance, particularly self-esteem and psychological distress. Importantly, educational aspirations had a strong association with actual achievement at age 16, remaining associated even after controlling for a number of other variables, including prior achievement. These findings are discussed in light of previous research and potential intervention strategies.
\end{abstract}

C. Rothon $(\bowtie) \cdot$ V. Cattell $\cdot$ S. Stansfeld

Centre for Psychiatry, Queen Mary University of London, Barts \& The London School of Medicine and Dentistry, Wolfson Institute of Preventive Medicine, Charterhouse Square,

London EC1M 6BQ, UK

e-mail: c.rothon@qmul.ac.uk

M. Arephin

Cancer Research UK, Centre for Epidemiology, Mathematics and Statistics, Queen Mary University of London, Barts \& The London School of Medicine and Dentistry, Wolfson Institute of Preventive Medicine, Charterhouse Square, London EC1M 6BQ, UK

E. Klineberg

Department of Social Medicine, University of Bristol, Canynge Hall, 39 Whatley Road,

Bristol BS8 2PS, UK 
Keywords Aspirations · Achievement $\cdot$ Adolescent $\cdot$ Education $\cdot$ Ethnic groups

A key international priority is to reduce gaps in educational outcomes. One way in which educational outcomes may be influenced is through the aspirations of students themselves. Indeed, previous research has shown that aspirations are one of the most significant factors in predicting final educational outcomes in terms of both participation and achievement; their development in adolescence is therefore an important topic for study (Sewell and Hauser 1993; Cheng and Starks 2002). Such work is likely to be essential, moreover, if we are to reverse a tendency to slowing social mobility evident in Britain (Milburn 2009).

\section{Educational aspirations and achievement at school}

There are a number of theoretical perspectives on the formation of educational aspirations and their impact on subsequent behaviour. In sociology, the dominant model linking aspirations and achievement was developed from the "status attainment model" (Blau and Duncan 1967). This model was based heavily on structural factors. It was extended by Sewell and colleagues to include social psychological predictors of educational and occupational achievement (Sewell and Shah 1967, 1968; Sewell and Hauser 1980, 1993; Sewell et al. 1980). This model sees young people's aspirations as a significant influence on their educational achievement and, later on, their occupational attainment. Indeed, these researchers identified aspirations as the most important factor having direct effects on educational level obtained.

There are two broad groups of factors which have been posited to influence aspirations in the first place: social dimensions and personal dimensions (Strand and Winston 2008). The social dimension places emphasis on family background and resources. The level of education achieved by one's parents has been shown to be an important determinant of educational ambition. Those with lower incomes or low parental levels of education may perceive education beyond compulsory level to be beyond their reach and therefore reduce their aspirations (Sewell and Hauser 1980; Teachman 1987). However, measures such as family income and parental education have been criticised for failing to capture the full range of processes likely to be related to the development of educational aspirations in young people (Teachman and Paasch 1998). The personal dimension centres on students' perceptions of their own attributes, as well as the influence of "significant others". Psychological health and self-esteem might be expected to be key aspects of this; it would be anticipated that poor psychological health will lead to lower aspirations because of its association with poor motivation, lack of energy and reduced expectations. The roots of the "significant others" explanation lies in the symbolic interactionist tradition, most commonly associated with the work of Mead (1934). This theory centres around the idea that human beings act on the basis of the meanings that things have for them, and that these meanings are developed from their social interaction with others (Blumer 1937). The role of parents has been seen as particularly important, as they are well placed to support and encourage young people (Garg et al. 2002; Marjoribanks 2002; Mau and Bikos 2000; Sewell and Shah 1968; Teachman and Paasch 1998). 
Croll (2008) has pointed to the limitations of structural approaches, arguing that although people from advantaged backgrounds are typically over-represented in advantaged destinations, there are many exceptions to this. He notes an increasing tendency in the literature to focus on the role of individual choice (albeit constrained by social background) in influencing eventual destinations (Croll 2008). Qualitative work provides support for the importance of individual agency in influencing aspirations and the choices made, even in cases where eventual occupational choices are closely aligned with social background. A South London study noted a sense of "purposefulness" in the young people interviewed, even when their circumstances acted as a heavily limiting influence (Ball et al. 2000). Rational action theory also emphasises the importance of choice in educational aspirations, arguing that the educational decisions made by young people are based on a rational assessment of the educational options available to them, their costs and benefits, and perceived probability of success (Breen and Goldthorpe 1997; Goldthorpe 2000).

"Economic" models see aspirations as a rational assessment based on objective social and economic circumstances. Students' decisions are made on the basis of a combination of both "pull" (eg. potential for higher salary) and "push" (eg. avoiding unemployment) factors (Leslie and Drinkwater 1999). These models have been subject to some criticism, however, with some commentators stressing the need for economists to use more subjective data in studying expectations formation (Manski 1993).

In the psychological literature, developmental theory views vocational development as a process of creating and implementing a self-concept (Super 1953, 1969, 1980; Ginzberg et al. 1951). There are three main stages of this process for young people, starting in the early years and ending in young adulthood: fantasy, tentative, and realistic. At the fantasy stage there is little orientation based on reality; all possibilities are open. At the tentative stage, the young person is able to relate interests to future choices and assess their capacity for particular choices. During the realistic stage, choices are restricted based on preferences and abilities and a decision is made; the individual then pursues educational experiences which are in line with this goal. This theory has been criticised for a lack of attention to constraining factors related to social background, ethnicity and gender. In contrast, Bandura's social cognitive theory places emphasis on the constellation of factors contributing to aspirations: background, personal, and environmental factors (Bandura 1978).

An important focus of a substantial amount of research in the United States has been on variation in aspirations by ethnicity. In the US, research has shown that aspirations can vary by ethnic group and has usually shown that minority ethnic students have higher aspirations than white students (Cheng and Starks 2002; Goyette and Xie 1999; Kao and Tienda 1998). Research in Britain on differential aspirations by ethnicity has been more limited; the research that has been undertaken has found a similar pattern to that in the US. In a sample of pupils in schools in Rochdale, Asian pupils were found to be more likely to want to remain in the educational system beyond compulsory leaving age (Penn and Scattergood 1992). Amongst Year 10 pupils (age 14-15) in a London sample, white pupils were the least likely to want to go to university, whilst pupils from black African, black Caribbean and Asian backgrounds were more likely to hold this ambition (Addams and Johnson 2005). The most recent work on 
educational aspirations in Britain found some differences in aspirations by ethnic group, with black African and Pakistani pupils as well as the "Asian other" group having significantly higher aspirations than the white British group (Strand and Winston 2008).

An interesting question is how far differences in educational aspirations might help explain differential patterns of achievement by ethnicity. British research has found important differences by ethnicity in achievement levels, with higher achievement by Chinese and Indian pupils, and lower achievement by black, Pakistani and Bangladeshi pupils (Connolly 2006; Demack et al. 2000; Rothon 2007, 2008). Controlling for social class amplifies Indian achievement even further and explains much of the Pakistani and Bangladeshi deficit, but not that of black pupils (Rothon 2007, 2008). It is possible that differences in educational aspirations might further account for the patterns found.

"Aspirations", as used in this paper, refers to the desires and aims of young people. A distinction has sometimes been made between "aspirations" and "expectations". For example, it has been proposed that a distinction should be made between what a student hopes he/she will do and what they predict they will do (Brookover et al. 1967). Other authors have used aspirations to refer to the desires and aims of young people, and expectations to refer to what their parents desire for them (Williams 1972). No such distinction is made here. "Aspirations" refers solely to the stated aims of the young people. This paper looks at educational aspirations (as opposed to occupational aspirations), and specifically at the decision whether or not to remain in education after the age of 16 .

The current paper adds to the research by looking not only at variation in aspirations amongst a cohort of East London adolescents, but also at their impact on subsequent academic achievement.

The key questions asked in the paper which follows are:

1. What differences are there by gender, ethnicity and social class in aspiration to remain in education beyond compulsory level?

2. How do socio-psychological variables impact on aspirations?

3. How do aspirations impact on eventual achievement?

4. Can differential levels of educational aspiration explain gender, ethnic and social class differences in achievement?

5. Do educational aspirations remain an important predictor of achievement even when prior attainment is taken into account?

\section{Data and methods}

\subsection{Participants}

The data come from the Research with East London Adolescents: Community Health Survey (RELACHS), a school based epidemiological study of a representative sample of adolescents from Year 7 (11-12 years) and Year 9 (13-14 years) attending 28 comprehensive schools in Hackney, Newham, and Tower Hamlets in 2001 (Stansfeld et al. 2003). Further data were collected in 2003 and 2005. This paper looks at adolescents 
who took part in RELACHS whilst they were in Year 9. In 2001, 1408 Year 9 pupils took part in RELACHS and, in 2003, 1091 of the original Year 7 pupils (in 2003 in Year 9) were followed up, giving a total sample for this study of 2499. Of those pupils who did not participate, the majority were not available due to school absence, illness, or other school activities.

\subsection{Measures}

\subsubsection{Aspirations}

The item on aspirations asked respondents: "If you had a choice, what would you like to be doing when you are 16? (if you are 16, answer for what you think you will be doing next year)". Two measures of aspiration are used in this study: (1) remaining in education after the age of 16, and (2) doing A levels (the most academic route in Britain which has traditionally led to university entrance). The items that were taken to represent the desire to remain in education were as follows: doing A levels, doing some other course at school (6th form) or at College and getting an apprenticeship/ training/employment training course. Getting a full-time job, getting a part-time job, being unemployed and leaving school were coded as not aspiring to continue in education beyond the age of 16 .

\subsubsection{Psychological distress}

Psychological distress at age 13-14 was measured using the self report version of the Strengths and Difficulties Questionnaire (SDQ) (Goodman 1997). The questions form five scales: emotional symptoms, conduct problems, hyperactivity/inattention, peer relationship problems, and prosocial behaviour. A total SDQ score ranging from $0-40$ is generated by adding together the scores for all of the scales, apart from prosocial behaviour. The higher the total score, the higher the level of measured distress. A score of 18 was chosen as the threshold for a high scorer on the SDQ as this was equivalent to prevalence rates in national data using multi model assessments (Meltzer et al. 2003). The measure has been used previously in ethnically mixed youth samples which support the SDQ as a valid instrument for ethnically diverse samples (Leavey et al. 2004; Meltzer et al. 2003; Mullick and Goodman 2001; Muris et al. 2003).

\subsubsection{Depressive symptoms}

Depressive symptoms were measured using the Short Moods and Feelings Questionnaire (SMFQ) two years after the baseline survey (Angold et al. 1987). Statements about the emotions and behaviour of the respondent over the past 2 weeks were rated. Examples of items include: "I felt miserable or unhappy", "I didn't enjoy anything at all", "I cried a lot". There are 13 items in this scale: "true", and "sometimes true", or "not true". The scores for these items were summed to produce an overall magnitude of symptoms, with a score of 8 or above indicating the presence of depressive 
symptoms. In the original validation against the Diagnostic Interview Schedule for Children-Depressive Scale, this threshold yielded a positive predictive value to $80 \%$ and a negative predictive value of $68 \%$ (Angold et al. 1995). The Cronbach's alpha reliability coefficient for this sample is 0.90 .

\subsubsection{Self-esteem}

Self-esteem was measured using the Rosenberg Self-Esteem Scale (Rosenberg 1965). This is a self-administered 10-item Guttman scale; it provides a total score that indicates global self-esteem in adults and adolescents. The RSES has demonstrated concurrent, predictive and construct validity. It has a Guttman scale of 0.92 which indicates excellent reliability. Test-retest reliability evinces correlations of 0.85 and 0.88 over 2 weeks, showing excellent stability over time (Program Outcomes for Youth, University of Arizona, http://ag.arizona.edu/fcs/cyfernet/nowg/sc_ar_measures.html).

\subsubsection{Ethnicity}

Ethnicity was categorised as follows using a revised version of the 2001 census: white UK, Bangladeshi, Pakistani, Asian Indian, black African, black Caribbean, and other.

\subsubsection{Free school meals}

Pupils are eligible for free school meals if their parents receive Income Support, Income Based Jobseekers' Allowance, support under part VI of the Immigration and Asylum Act 1999, or (with some conditions) Child Tax Credit. Data on free school meals were collected from school records.

\subsubsection{Parental support with school}

Two items were used to assess parental support with school: "my parents encourage me to do well at school" and "if I have a problem at school my parents are ready to help". The responses "always" and "often" were deemed to represent a high level of parental encouragement. "Sometimes", "rarely" and "never" indicated a lower level of support.

\subsubsection{Social support}

The degree of social support derived from family and friends was measured at baseline using the Multidimensional Scale of Perceived Social Support (MSPSS) (Zimet et al. 1988). This is a 12 item scale which produces scores that measure levels of social support from three sources: family, friends and a significant other. Items included: "my family really tries to help me", "I can count on my friends when things go wrong", and "I can talk about my problems with my family". This scale has been found to have a 
high level of internal and test-retest reliability; the overall reliability coefficient is 0.88 (Zimet et al. 1988). The scale has been found to have good concurrent, construct and discriminant validity (Zimet et al. 1988). The Cronbach's alpha reliability coefficient for this sample is 0.90 . Social support scores were split into three equal sized groups (high, moderate and low support).

\subsubsection{Educational achievement}

The main educational outcome used here was the attainment of 5 or more General Certificate of Secondary Education Examinations (GCSEs) at grades A*-C (taken at age 15-16). Almost the entire cohort of students in this age group in England takes these examinations. Typically, students study 8 or 9 subjects, some of which are compulsory (for example English, Mathematics and Science). The benchmark of 5 or more GCSEs at grades A*-C is used by the Department of Education and Skills as an indicator of adequate performance (Department for Education and Skills 2006). Schools varied in the way in which they recorded the results; 690 scores for the 5 or more A*-C grades variable were estimated using SPSS from a "total points" at GCSE measure, using the Expectation-Maximisation (EM) Algorithm.

The benchmark used for educational achievement at age 13-14 was the attainment of level 5 or above in English, mathematics and science in the Key Stage 3 examinations. These are national tests, intended to indicate if a student is working at the target level for their age. Data on educational achievement at Key Stage 3 and GCSE were obtained from Local Education Authorities.

\subsection{Procedure}

All 42 schools in the three London boroughs were stratified by borough and school type (comprehensive, voluntary, other). Thirty schools were randomly selected. Head teachers were informed about the study and asked for permission for their school to participate. Two schools declined to take part. Within the 28 schools that agreed to take part, four representative, mixed ability classes were selected (two from Year 7 and two from Year 9). The overall response rate was $84 \%$ at baseline. Information sheets explaining the study were given to teachers, parents, and pupils a week before the visit to the school. Parents were given the opportunity to opt their child out of the study, and pupils gave fully informed consent on the day. A team of researchers administered the questionnaire in classrooms in one session of 40-50 minutes. One member of the team led the class, explaining the questionnaire and providing assurance that all answers would be anonymous and confidential. Three or four additional researchers assisted, answering queries, ensuring that participants did not confer and checking for missing data on completion of the questionnaires. These methods were used at both data collection phases. Meetings were held with a community advisory group, consisting of teachers, parents, health and social care professionals, to advise on ethical aspects of the work and on the research process. The study protocol was approved by the East London and the City Local Research Ethics Committee. 


\subsection{Statistical analysis}

Because the primary sampling unit for the study was the school, it was necessary to make adjustments for the clustered survey design in the analyses. Failing to adjust for this would result in an overstatement of precision by ignoring the possible lack of independence of observations within the same school. Adjustments were made for survey design using the svy commands in Stata. An equal number of classes was selected in each school regardless of school size, so that probability of selection varied by school. Data were reweighted to ensure that the data were representative of all adolescents attending comprehensive schools in the three boroughs at the time of the baseline survey.

Missing data were assessed using crosstabulation and the chi-squared option in Stata. Odds ratios and confidence intervals were calculated using the Stata logistic regression command.

\section{Results}

\subsection{The sample}

Table 1 describes the sample. There was a similar number of boys and girls in the sample; $48.5 \%$ (1210) were boys. The sample was deprived and ethnically diverse.

Table 1 Descriptive statistics

\begin{tabular}{lrr}
\hline & $N$ & $\%$ \\
\hline Aspires to remain in education & & \\
No & 688 & 27.6 \\
Yes & 1,809 & 72.5 \\
Aspires to do A levels & & \\
No & 1,081 & 43.3 \\
Yes & 1,416 & 56.7 \\
Achieved 5 or more A*-C grades at GCSE & & \\
No & 889 & 44.6 \\
Yes & 1,103 & 55.4 \\
Achieved Level 5 or above at KS3 & & \\
No & 800 & 59.4 \\
Yes & 546 & 40.6 \\
Gender & & \\
Male & 1,210 & 48.5 \\
Female & 1,287 & 51.5 \\
Ethnicity & & \\
White UK & 494 & 19.8 \\
Bangladeshi & 647 & 26.0 \\
Asian Indian & 232 & 9.3 \\
Pakistani & 163 & 6.5 \\
\hline
\end{tabular}


Table 1 continued

\begin{tabular}{|c|c|c|}
\hline & $N$ & $\%$ \\
\hline Black Caribbean & 150 & 6.0 \\
\hline Black African & 251 & 10.0 \\
\hline Other & 554 & 22.2 \\
\hline \multicolumn{3}{|c|}{ Eligible for Free School Meals } \\
\hline Not eligible & 1,261 & 51.9 \\
\hline Eligible & 1,171 & 48.2 \\
\hline \multicolumn{3}{|l|}{ Psychological distress (SDQ) } \\
\hline Not a case & 2,193 & 89.2 \\
\hline Case & 267 & 10.9 \\
\hline \multicolumn{3}{|c|}{ Depressive symptoms (SMFQ) } \\
\hline Not a case & 1,743 & 74.7 \\
\hline Case & 590 & 25.3 \\
\hline \multicolumn{3}{|c|}{ Parents help with problems at school } \\
\hline Sometimes/rarely/never & 440 & 18.2 \\
\hline Always/often & 1,973 & 81.8 \\
\hline \multicolumn{3}{|c|}{ Parents encourage to do well at school } \\
\hline Sometimes/rarely/never & 136 & 5.6 \\
\hline Always/often & 2,289 & 94.4 \\
\hline \multicolumn{3}{|l|}{ Family social support } \\
\hline Low & 715 & 32.8 \\
\hline Moderate & 692 & 31.7 \\
\hline High & 773 & 35.5 \\
\hline \multicolumn{3}{|l|}{ Friends social support } \\
\hline Low & 652 & 29.9 \\
\hline Moderate & 750 & 34.4 \\
\hline High & 778 & 35.7 \\
\hline
\end{tabular}

Nearly half of the pupils were eligible for free school meals $(1171,48.2 \%)$. The largest ethnic group represented was Bangladeshi (647, 26.0\%); 19.8\% (494) of the sample were of white UK origin; 9.3\% (232) Asian Indian; 6.5\% (163) Pakistani; 6.0\% (150) black Caribbean; $10.0 \%$ (251) black African; and 22.2\% (554) of other ethnic origin.

The proportion of pupils aged 13-14 who stated a desire to remain in education after the age of 16 was $72.5 \%$ (1809). Of the sample, $56.7 \%$ (1416) aspired to do A levels and $55.4 \%$ (1103) achieved the government benchmark of 5 or more $\mathrm{A}^{*} \mathrm{C}$ grades at GCSE. Regarding the mental health measures, 10.9\% (267) scored over the threshold for psychological distress on the SDQ, and 25.3\% (590) scored over the threshold for depressive symptoms. A large number of students reported high levels of support from parents in relation to school; 81.8\% (1973) reported that their parents "always" or "often" helped them if they had a problem at school, and 94.4\% (2289) said that their parents encouraged them to do well at school "always" or "often". Only $40.6 \%$ (546) of the sample achieved the academic benchmark at Key Stage 3. 


\subsection{Univariable analysis: remaining in education post-16}

Table 2 shows univariable logistic regression analyses looking at the association between aspirations and key variables. There was strong evidence that girls were more likely to want to remain in education than boys $(p=0.006)$. Girls had about one and a half times the odds of wishing to remain in education, compared with boys $(\mathrm{OR}=1.61,95 \% \mathrm{CI} 1.16,2.23)$. There was some evidence that Asian Indian pupils ( $p=0.019)$ and weak evidence that Pakistani pupils $(p=0.094)$ were more likely to wish to remain in education. Both groups had about one and a half times the odds of wanting to remain in education post-16 (Indian pupils: $\mathrm{OR}=1.58,95 \% \mathrm{CI} 1.08,2.30$; Pakistani pupils: $\mathrm{OR}=1.51,95 \%$ CI $0.93,2.46)$. Social background seems to play a part. There was strong evidence that pupils who were eligible to receive free school meals had lower odds of aspiring to remain in education post-16 $(p<0.0001)$. Pupils who were eligible for free school meals were just over half as likely to want to remain in education compared with pupils not eligible for free school meals $(\mathrm{OR}=0.62,95 \%$ CI 0.51, 0.76).

Socio-psychological variables had varying levels of importance in predicting an aspiration to remain in education after age 16 at the univariable level. There was strong evidence that psychological distress was associated with lower educational aspirations $(p=0.003)$. Those who scored above the threshold for psychological distress had about a third lower odds of wanting to remain in education post-16 compared with those that did not score above the threshold $(\mathrm{OR}=0.64,95 \% 0.48,0.84)$. There was weaker evidence for an association between depressive symptoms and educational aspirations ( $p=0.062$ ), and the effect was smaller, with those exhibiting depressive symptoms having $25 \%$ lower odds of wanting to remain in education $(\mathrm{OR}=0.75,95 \% \mathrm{CI} 0.55$, 1.02). Self-esteem was also associated with the odds of aspiring to remain in postcompulsory education; those with moderate levels of self-esteem were about a third less likely than those with high self-esteem to state that they wanted to remain in education $(\mathrm{OR}=0.66,95 \%$ CI $0.49,0.89)$, and those with low self-esteem had about half the odds of wanting to remain in education beyond the compulsory level $(\mathrm{OR}=0.49$, $95 \%$ CI $0.38,0.65)$. There was evidence that parental support was associated with an aspiration to remain in education. There was particularly strong evidence for an association between parental encouragement to do well at school and pupils' educational aspirations $(p<0.0001)$. Pupils whose parents most often encouraged them had two and a half times the odds of wishing to remain in education post-16 compared to those pupils whose parents only "sometimes", "rarely" or "never" encouraged them to do well at school $(\mathrm{OR}=2.38,95 \% \mathrm{CI} 1.61,3.52)$. There was very strong evidence that high levels of social support from friends also resulted in higher odds of wanting to remain in education $(p<0.0001)$. Those with high levels of social support from friends had $78 \%$ greater odds of wanting to remain in education after the age of 16 $(\mathrm{OR}=1.78,95 \%$ CI 1.42, 2.24).

There was very strong evidence for an association between academic achievement and aspirations $(p<0.0001)$. Those who reached the achievement benchmark had around 4 times the odds of wanting to remain in education after the age of 16 $(\mathrm{OR}=4.02,95 \%$ CI 2.94, 5.50). 
Table 2 Association of key variables with aspiration to do A levels and remain in education after the age of 16: univariable analysis

\begin{tabular}{|c|c|c|c|c|}
\hline & $\begin{array}{l}\text { OR }(95 \% \mathrm{CI}) \\
\text { aspiration to do A } \\
\text { levels }\end{array}$ & $p$-value & $\begin{array}{l}\text { OR }(95 \% \mathrm{CI}) \\
\text { aspiration to } \\
\text { remain in } \\
\text { education post-16 }\end{array}$ & $p$-value \\
\hline \multicolumn{5}{|l|}{ Gender } \\
\hline Male & 1 & & 1 & \\
\hline Female & $1.08(0.84,1.38)$ & 0.531 & $1.61(1.16,2.23)$ & 0.006 \\
\hline \multicolumn{5}{|l|}{ Ethnicity } \\
\hline White UK & 1 & & 1 & \\
\hline Bangladeshi & $1.43(1.09,1.89)$ & 0.013 & $1.09(0.74,1.59)$ & 0.653 \\
\hline Asian Indian & $2.18(1.57,3.02)$ & $<0.0001$ & $1.58(1.08,2.30)$ & 0.019 \\
\hline Pakistani & $1.88(1.16,3.05)$ & 0.012 & $1.51(0.93,2.46)$ & 0.094 \\
\hline Black Caribbean & $1.10(0.75,1.63)$ & 0.149 & $0.95(0.52,1.74)$ & 0.863 \\
\hline Black African & $1.33(0.97,1.82)$ & 0.074 & $0.96(0.65,1.41)$ & 0.812 \\
\hline Other & $1.34(0.93,1.93)$ & 0.116 & $0.93(0.71,1.23)$ & 0.598 \\
\hline \multicolumn{5}{|l|}{ Eligible for FSM } \\
\hline Not eligible & 1 & & 1 & \\
\hline Eligible & $0.78(0.64,0.95)$ & 0.014 & $0.62(0.51,0.76)$ & $<0.0001$ \\
\hline \multicolumn{5}{|l|}{ Psychological distress } \\
\hline Not a case & 1 & & 1 & \\
\hline Case & $0.78(0.59,1.03)$ & 0.073 & $0.64(0.48,0.84)$ & 0.003 \\
\hline \multicolumn{5}{|l|}{ Depressive symptoms } \\
\hline Not a case & 1 & & 1 & \\
\hline Case & $0.86(0.67,1.12)$ & 0.256 & $0.75(0.55,1.02)$ & 0.062 \\
\hline \multicolumn{5}{|l|}{ Self-esteem } \\
\hline High & 1 & & 1 & \\
\hline Moderate & $0.74(0.58,0.95)$ & 0.021 & $0.66(0.49,0.89)$ & 0.008 \\
\hline Low & $0.55(0.43,0.70)$ & $<0.0001$ & $0.49(0.38,0.65)$ & $<0.0001$ \\
\hline \multicolumn{5}{|l|}{ Parents help with problems } \\
\hline Sometimes/rarely/never & 1 & & 1 & \\
\hline Always/often & $1.24(1.04,1.47)$ & 0.018 & $1.23(0.94,1.62)$ & 0.119 \\
\hline \multicolumn{5}{|l|}{ Parents encourage to do well } \\
\hline Sometimes/rarely/never & 1 & & 1 & \\
\hline Always/often & $1.79(1.25,2.54)$ & 0.002 & $2.38(1.61,3.52)$ & $<0.0001$ \\
\hline \multicolumn{5}{|l|}{ Family social support } \\
\hline Low & 1 & & 1 & \\
\hline Moderate & $1.20(0.98,1.47)$ & 0.076 & $1.33(0.97,1.82)$ & 0.076 \\
\hline High & $1.18(0.97,1.44)$ & 0.090 & $1.34(1.04,1.73)$ & 0.026 \\
\hline
\end{tabular}


Table 2 continued

\begin{tabular}{llllr}
\hline & $\begin{array}{l}\text { OR }(95 \% \mathrm{CI}) \\
\text { aspiration to do A } \\
\text { levels }\end{array}$ & $p$-value & $\begin{array}{l}\text { OR }(95 \% \mathrm{CI}) \\
\text { aspiration to } \\
\text { remain in } \\
\text { education post-16 }\end{array}$ & $p$-value \\
\hline $\begin{array}{l}\text { Friends social support } \\
\text { Low }\end{array}$ & 1 & & 1 & 0.061 \\
$\quad \begin{array}{l}\text { Moderate } \\
\text { High }\end{array}$ & $1.01(0.82,1.26)$ & 0.891 & $1.26(0.99,1.61)$ & $<0.0001$ \\
$\begin{array}{l}\text { Level 5 or above at KS3 } \\
\text { No }\end{array}$ & $1.33(1.06,1.67)$ & 0.015 & $1.78(1.42,2.24)$ & \\
$\quad$ Yes & $2.33(1.67,3.25)$ & $<0.0001$ & $4.02(2.94,5.50)$ & $<0.0001$ \\
\hline
\end{tabular}

\subsection{Univariable analysis: doing A levels}

For the traditional academic route of A levels, there was no evidence for a gender difference in aspiration $(p=0.531)$. However, ethnic differences in aspiration to do A levels were more marked than for the more general measure of remaining in education after the age of 16. All three Asian groups, as well as black African students evinced a stronger desire to do A levels than white UK students. The strongest effect was for Asian Indian students, who had more than twice the odds of aspiring to do A levels $(\mathrm{OR}=2.18,95 \%$ 1.57, 3.02), compared with white pupils. Receiving free school meals resulted in slightly lower odds of aspiring to do A levels $(\mathrm{OR}=0.78$, 95\% CI 0.64, 0.95).

The odds ratios for parental help with problems at school, parental encouragement, and social support from friends and family in relation to this second outcome were similar to those for wanting to remain in compulsory education beyond age 16 . However, there was only weak evidence that psychological distress $(p=0.073)$ and no evidence that depressive symptoms $(p=0.256)$ were associated with aspiring to do A levels. Self-esteem did appear to have an impact; those with low self-esteem were about half as likely to aspire to do A levels as those with high levels of self-esteem $(\mathrm{OR}=0.55,95 \%$ CI $0.43,0.70)$.

As with staying on in education after the age of 16, there was strong evidence that academic achievement at Key Stage 3 was associated with a desire to do A levels $(p<0.0001)$. Those who had reached the benchmark had approximately two and a half times the odds of wishing to do A levels, compared to those who had not reached the benchmark $(\mathrm{OR}=2.33,95 \%$ CI $1.67,3.25)$.

\subsection{Univariable analysis: gaining 5 or more $\mathrm{A}^{*}-\mathrm{C}$ grades at GCSE}

Table 3 shows the association between achievement at GCSE and key variables. Aspiring to remain in education post-16 was a strong predictor of achieving the national benchmark of 5 or more $\mathrm{A}^{*}$-C grades at GCSE $(p<0.0001)$. Indeed, with the 
exception of Key Stage 3 achievement, it was the strongest predictor of success at GCSE level. Pupils who stated a wish to continue in education had more than three times the odds of achieving the benchmark $(\mathrm{OR}=3.33,95 \% \mathrm{CI} 2.55,4.36)$. Aspiring to do A levels also had an impact on GCSE success, with those wanting to do A levels having more than twice the odds of achieving 5 or more $\mathrm{A}^{*}-\mathrm{C}$ grades $(\mathrm{OR}=2.30$, 95\% CI 1.85, 2.85).

Socio-demographic variables were also of importance. There was strong evidence $(p=0.004)$ that girls had nearly twice the odds of boys of reaching the GCSE benchmark $(\mathrm{OR}=1.72,95 \% \mathrm{CI} 1.20,2.45)$. There was no evidence for any ethnic group performing at a significantly different level to the white UK group, with the exception of pupils of Indian ethnicity, who had higher odds of achieving the benchmark $(\mathrm{OR}=1.70,95 \%$ CI $1.08,2.67)$. There was strong evidence $(p=0.006)$ that those who were eligible for free school meals had lower achievement. Those eligible had about two-thirds of the odds of achieving 5 or more $\mathrm{A} *-\mathrm{C}$ grades at GCSE compared to those not eligible for free school meals $(\mathrm{OR}=0.67,95 \% \mathrm{CI} 0.52,0.88)$.

There was some evidence that pupils who received high levels of encouragement from their parents had higher odds of achieving the GCSE benchmark ( $p=0.026)$. Those pupils whose parents often or always encouraged them to do well at school had more than one and a half times the odds of achieving 5 or more $\mathrm{A} *$ - $\mathrm{C}$ grades $(\mathrm{OR}=1.59,95 \% \mathrm{CI} 1.06,2.37)$. There was weak evidence that pupils whose parents encouraged them to do well at school had higher odds of achieving the benchmark $(\mathrm{OR}=1.24,95 \%$ CI $0.99,1.56 ; p=0.056)$. There was no evidence for social support being an important predictor of GCSE achievement.

There was strong evidence for psychological distress as a predictor of GCSE achievement ( $p=0.001)$, with those defined as a "case" on the SDQ having about half the odds of achieving the GCSE benchmark ( $\mathrm{OR}=0.60,95 \%$ CI $0.45,0.80)$. There was no evidence for depressive symptoms having the same negative impact, however. There was very strong evidence for an association between GCSE achievement and self-esteem $(p<0.0001)$, with those with low self-esteem scores having less than half the odds of reaching the attainment benchmark compared to those with high self-esteem $(\mathrm{OR}=0.46,95 \%$ CI $0.36,0.60)$.

As would be expected, there was strong evidence for prior high achievement increasing the odds of success at GCSE ( $p<0.0001)$. Pupils who had achieved the government benchmark at Key Stage 3 had more than seven times the odds of achieving the GCSE benchmark (OR $=7.16,95 \%$ CI 4.67, 10.98) compared to those who had not achieved the Key Stage 3 benchmark.

\subsection{Multivariable analysis: gaining 5 or more $\mathrm{A}^{*} \mathrm{C}$ grades at GCSE}

Two sets of multivariable models were conducted, one using the aspiration to remain in education beyond the age of 16 variable as a control (Table 4), and the other using the aspiration to do A levels variable (Table 5). The background variables of gender, ethnicity, and eligibility for free school meals were entered in model 1 . There was strong evidence for a gender difference in achievement at GCSE, with females having about $74 \%$ greater odds of achieving the benchmark $(\mathrm{OR}=1.74,95 \% \mathrm{CI} 1.22,2.48)$. 
Table 3 Association of key variables with achieving 5 or more A*-C grades at GCSE: univariable analysis

\begin{tabular}{|c|c|c|c|}
\hline & Odds ratio $(95 \% \mathrm{CI})$ & $p$-value & $N$ \\
\hline Aspiration to remain in education post- 16 & & & 1,992 \\
\hline No & 1 & & \\
\hline Yes & $3.33(2.55,4.36)$ & $<0.0001$ & \\
\hline Aspiration to do A levels & & & 1,992 \\
\hline No & 1 & & \\
\hline Yes & $2.30(1.85,2.85)$ & $<0.0001$ & \\
\hline Gender & & & 1,992 \\
\hline Male & 1 & & \\
\hline Female & $1.72(1.20,2.45)$ & 0.004 & \\
\hline Ethnicity & & & 1,987 \\
\hline UK White & 1 & & \\
\hline Bangladeshi & $1.27(0.78,2.05)$ & 0.318 & \\
\hline Indian & $1.70(1.08,2.67)$ & 0.023 & \\
\hline Pakistani & $0.89(0.52,1.52)$ & 0.665 & \\
\hline Black & $0.94(0.58,1.53)$ & 0.808 & \\
\hline Black & $1.24(0.69,2.25)$ & 0.460 & \\
\hline Other & $1.37(0.91,2.06)$ & 0.122 & \\
\hline Eligibility for free school meals & & & 1,968 \\
\hline Not eligible & 1 & & \\
\hline Eligible & $0.67(0.52,0.88)$ & 0.006 & \\
\hline Parents encourage to do well at school & & & 1,950 \\
\hline Sometimes/rarely/never & 1 & & \\
\hline Often/always & $1.59(1.06,2.37)$ & 0.026 & \\
\hline Parents help with problems at school & & & 1,941 \\
\hline Sometimes/rarely/never & 1 & & \\
\hline Often/always & $1.24(0.99,1.56)$ & 0.056 & \\
\hline Family social support & & & 1,756 \\
\hline Low & 1 & & \\
\hline Moderate & $0.88(0.71,1.09)$ & 0.216 & \\
\hline High & $0.87(0.69,1.10)$ & 0.226 & \\
\hline Friends social support & & & 1,756 \\
\hline Low & 1 & & \\
\hline Moderate & $1.14(0.91,1.42)$ & 0.250 & \\
\hline High & $1.03(0.78,1.35)$ & 0.834 & \\
\hline Psychological distress & & & 1,968 \\
\hline Not a case & 1 & & \\
\hline Case & $0.60(0.45,0.80)$ & 0.001 & \\
\hline Depressive symptoms & & & 1,881 \\
\hline Not a case & 1 & & \\
\hline Case & $0.83(0.66,1.05)$ & 0.116 & \\
\hline
\end{tabular}


Table 3 continued

\begin{tabular}{llcc}
\hline & Odds ratio $(95 \% \mathrm{CI})$ & $p$-value & $N$ \\
\hline Self esteem & & & 1,882 \\
$\quad$ High & 1 & & \\
Moderate & $0.64(0.51,0.81)$ & 0.001 & \\
Low & $0.46(0.36,0.60)$ & $<0.0001$ & 1,205 \\
Level 5 or above at KS3 & & $<0.0001$ & \\
No & 1 & & \\
$\quad$ Yes & $7.16(4.67,10.98)$ & & \\
\hline
\end{tabular}

There was also some evidence that adolescents of Indian ethnicity had higher levels of achievement $(\mathrm{OR}=1.61,95 \%$ CI 1.08, 2.38). Eligibility for free school meals was also an important predictor, with those eligible around half as likely to achieve 5 or more $\mathrm{A} *$-C grades at GCSE $(\mathrm{OR}=0.63,95 \%$ CI $0.44,0.89)$.

Model 2a included the aspiration to remain in education beyond the age of 16 variable. In this multivariable model, those who aspire to remain in education after age 16 have more than three times the odds of achieving the national benchmark at GCSE $(\mathrm{OR}=3.17,95 \% \mathrm{CI} 2.45,4.09)$. Adding the aspirations variable had little effect on the odds ratio for gender. Girls still had higher odds of achieving the benchmark; higher aspirations do not "explain" their higher achievement. Similarly, there is little change in the odds ratio for eligibility for free school meals. Lower achievement amongst those receiving free school meals is not solely due to lower aspirations in this group. The ethnicity variables also change little with the addition of the aspirations variable. Asian Indians and the "other" ethnic groups both perform better than the white UK group at GCSE, even when their educational aspirations are taken into account.

In model $3 \mathrm{a}$, the psychological variables are added. This results in an improvement in model fit (adjusted Wald test $p$-value $=0.0002$ ). Depressive symptoms are not associated with achievement in the multivariable model. There is evidence for an association between psychological distress and achievement; those defined as a case on the SDQ have about a third lower odds of achieving the GCSE benchmark $(\mathrm{OR}=0.67,95 \% \mathrm{CI} 0.47,0.94)$. Self-esteem is also associated with achievement in the multivariable analysis. Those with moderate self-esteem have about two thirds of the odds of achieving the benchmark, compared with those with high self-esteem $(\mathrm{OR}=0.64,95 \% \mathrm{CI} 0.48,0.87)$. Those with low self-esteem have about half the odds of achieving the benchmark, compared with those with high self-esteem $(\mathrm{OR}=0.44$, $95 \%$ CI $0.30,0.63)$. There is a slight increase in the odds ratio for females from model 2 to model 3; this indicates that girls do better at GCSE despite the fact that they have higher odds of psychological difficulties. Once the psychological variables have been controlled for, girls have almost twice the odds of achieving 5 or more $\mathrm{A}^{*} \mathrm{C}$ grades at $\mathrm{GCSE}(\mathrm{OR}=1.86,95 \%$ CI $1.31,2.64)$.

Model $4 \mathrm{a}$ includes the variables relating to parental support with school. These do not result in any improvement in model fit, and there is little impact on the other variables in the model. Neither of the parental support variables is associated with achievement in the multivariable model. 
Table 4 Association of key variables with achieving 5 or more A*-C grades at GCSE: multivariable analysis

\begin{tabular}{|c|c|c|c|c|}
\hline & Model 1 & Model 2a & Model 3a & Model 4a \\
\hline \multicolumn{5}{|l|}{ Aspire to remain in education } \\
\hline No & & 1 & 1 & 1 \\
\hline Yes & & $3.17(2.45,4.09)$ & $2.93(2.23,3.83)$ & $2.91(2.22,3.82)$ \\
\hline \multicolumn{5}{|l|}{ Gender } \\
\hline Male & 1 & 1 & 1 & 1 \\
\hline Female & $1.74(1.22,2.48)$ & $1.67(1.19,2.34)$ & $1.86(1.31,2.64)$ & $1.87(1.32,2.64)$ \\
\hline \multicolumn{5}{|l|}{ Ethnicity } \\
\hline White UK & 1 & 1 & 1 & 1 \\
\hline Bangladeshi & $1.45(0.87,2.43)$ & $1.41(0.84,2.36)$ & $1.51(0.91,2.52)$ & $1.52(0.91,2.53)$ \\
\hline Asian Indian & $1.61(1.08,2.38)$ & $1.59(1.05,2.39)$ & $1.74(1.13,2.66)$ & $1.75(1.14,2.68)$ \\
\hline Pakistani & $0.92(0.50,1.70)$ & $0.86(0.47,1.58)$ & $0.88(0.47,1.64)$ & $0.88(0.47,1.64)$ \\
\hline Black Caribbean & $0.94(0.60,1.49)$ & $0.90(0.58,1.40)$ & $0.80(0.49,1.32)$ & $0.80(0.49,1.32)$ \\
\hline Black African & $1.49(0.75,2.97)$ & $1.38(0.70,2.70)$ & $1.32(0.66,2.64)$ & $1.32(0.66,2.66)$ \\
\hline Other & $1.70(1.10,2.61)$ & $1.64(1.08,2.47)$ & $1.65(1.07,2.54)$ & $1.65(1.07,2.54)$ \\
\hline \multicolumn{5}{|l|}{ Eligible for FSM } \\
\hline No & 1 & 1 & 1 & 1 \\
\hline Yes & $0.63(0.44,0.89)$ & $0.66(0.46,0.94)$ & $0.66(0.46,0.94)$ & $0.66(0.46,0.94)$ \\
\hline \multicolumn{5}{|l|}{ Psychological distress } \\
\hline Not a case & & & 1 & 1 \\
\hline Case & & & $0.67(0.47,0.94)$ & $0.67(0.47,0.95)$ \\
\hline \multicolumn{5}{|l|}{ Depressive symptoms } \\
\hline Not a case & & & 1 & 1 \\
\hline Case & & & $1.09(0.81,1.47)$ & $1.09(0.80,1.47)$ \\
\hline \multicolumn{5}{|l|}{ Self-esteem } \\
\hline High & & & 1 & 1 \\
\hline Moderate & & & $0.64(0.48,0.87)$ & $0.64(0.48,0.87)$ \\
\hline Low & & & $0.44(0.30,0.63)$ & $0.44(0.30,0.63)$ \\
\hline \multicolumn{5}{|l|}{ Parents help with problems } \\
\hline Sometimes/rarely/never & & & & 1 \\
\hline Always/often & & & & $1.12(0.72,1.73)$ \\
\hline \multicolumn{5}{|l|}{ Parents encourage to do well } \\
\hline Sometimes/rarely/never & & & & 1 \\
\hline Always/often & & & & $0.99(0.76,1.30)$ \\
\hline$N$ & 1,646 & 1,646 & 1,646 & 1,646 \\
\hline Adj Wald test $p$-value & & $<0.0001$ & 0.0002 & 0.8820 \\
\hline
\end{tabular}

Importantly, an aspiration to stay in education beyond age 16 remained associated with academic achievement after controlling for background variables, psychological variables and social support (results not shown). Analysis was undertaken on a smaller sample of pupils $(N=958)$ for whom information was available on Key Stage 
Table 5 Association of key variables with achieving 5 or more A*-C grades at GCSE: multivariable analysis

\begin{tabular}{|c|c|c|c|c|}
\hline & Model 1 & Model 2b & Model 3b & Model 4b \\
\hline \multicolumn{5}{|l|}{ Aspire to do A levels } \\
\hline No & & 1 & 1 & 1 \\
\hline Yes & & $2.04(1.64,2.54)$ & $1.92(1.55,2.40)$ & $1.92(1.54,2.40)$ \\
\hline \multicolumn{5}{|l|}{ Gender } \\
\hline Male & 1 & 1 & 1 & 1 \\
\hline Female & $1.74(1.22,2.48)$ & $1.78(1.24,2.53)$ & $1.97(1.37,2.84)$ & $1.98(1.38,2.86)$ \\
\hline \multicolumn{5}{|l|}{ Ethnicity } \\
\hline White UK & 1 & 1 & 1 & 1 \\
\hline Bangladeshi & $1.45(0.87,2.43)$ & $1.35(0.81,2.23)$ & $1.46(0.88,2.40)$ & $1.46(0.89,2.41)$ \\
\hline Asian Indian & $1.61(1.08,2.38)$ & $1.44(0.96,2.16)$ & $1.60(1.05,2.43)$ & $1.61(1.06,2.45)$ \\
\hline Pakistani & $0.92(0.50,1.70)$ & $0.83(0.45,1.53)$ & $0.85(0.45,1.59)$ & $0.85(0.45,1.60)$ \\
\hline Black Caribbean & $0.94(0.60,1.49)$ & $0.90(0.57,1.42)$ & $0.81(0.48,1.35)$ & $0.81(0.48,1.35)$ \\
\hline Black African & $1.49(0.75,2.97)$ & $1.33(0.67,2.66)$ & $1.28(0.63,2.61)$ & $1.28(0.63,2.61)$ \\
\hline Other & $1.69(1.10,2.61)$ & $1.54(1.01,2.35)$ & $1.56(1.00,2.42)$ & $1.56(1.00,2.42)$ \\
\hline \multicolumn{5}{|l|}{ Eligible for FSM } \\
\hline No & 1 & 1 & 1 & 1 \\
\hline Yes & $0.63(0.44,0.89)$ & $0.63(0.44,0.89)$ & $0.62(0.43,0.90)$ & $0.62(0.43,0.90)$ \\
\hline \multicolumn{5}{|l|}{ Psych distress } \\
\hline Not a case & & & 1 & 1 \\
\hline Case & & & $0.65(0.46,0.91)$ & $0.65(0.46,0.91)$ \\
\hline \multicolumn{5}{|l|}{ Depressive symptoms } \\
\hline Not a case & & & 1 & 1 \\
\hline Case & & & $1.08(0.81,1.43)$ & $1.08(0.81,1.44)$ \\
\hline \multicolumn{5}{|l|}{ Self-esteem } \\
\hline High & & & 1 & 1 \\
\hline Moderate & & & $0.64(0.48,0.86)$ & $0.64(0.48,0.86)$ \\
\hline Low & & & $0.43(0.30,0.61)$ & $0.43(0.30,0.62)$ \\
\hline \multicolumn{5}{|l|}{ Parents help with problems } \\
\hline Sometimes/rarely/never & & & & 1 \\
\hline Always/Often & & & & $0.97(0.74,1.26)$ \\
\hline \multicolumn{5}{|l|}{ Parents encourage to do well } \\
\hline Sometimes/rarely/never & & & & 1 \\
\hline Always/Often & & & & $1.22(0.79,1.90)$ \\
\hline$N$ & 1,646 & 1,646 & 1,646 & 1,646 \\
\hline Adj Wald test $p$-value & & $<0.0001$ & 0.0001 & 0.6476 \\
\hline
\end{tabular}

3 achievement (examinations taken at age 14). It was found that aspirations remained associated with achievement at GCSE even when controlling for performance at Key Stage 3. Those who aspired to remain in education had more than three times the odds 
of achieving the academic benchmark at $\operatorname{GCSE}(2.79,95 \%$ CI 1.68, 4.65). No ethnicity coefficients remained statistically significant after controlling for prior achievement.

The second set of multivariable models showed a very similar pattern of results to the first set of models (Table 5). As model $2 \mathrm{~b}$ indicates, an aspiration to do A levels did not "explain" higher achievement by girls or those not eligible for free school meals. However, the addition of the aspirations variable in model $2 b$ does result in some change in the strength of the evidence for Asian Indians' higher performance; once aspirations have been taken into account, there is much weaker evidence for this group having higher odds of achieving 5 or more $\mathrm{A}^{*} \mathrm{C}$ grades at GCSE ( $p=0.077$ ). The higher aspirations of Asian Indians, therefore, may in part explain their higher achievement at GCSE. Adding the psychological variables in model $3 \mathrm{~b}$ results in a slightly raised odds ratio for girls, as before, indicating that girls perform better at GCSE despite scoring higher on the measures of psychological difficulty. Parental support variables have no association with achievement in this multivariable model (model 4b).

As with the first set of multivariable analysis, an important finding was that aspirations remained associated with achievement even after controlling for a number of other variables. This also held when controlling for prior achievement in a more limited sample $(N=958)$. Those who aspired to do A levels were more than twice as likely to achieve the GCSE benchmark when controlling for background, psychological variables and Key Stage 3 performance $(\mathrm{OR}=2.25,95 \%$ CI 1.67, 3.03).

\section{Discussion and conclusion}

This paper found important differences in aspirations depending on individual characteristics. Although no gender difference was evident in aspiration to do A levels, girls were more likely than boys to express a wish to remain in education beyond the age of 16 more generally. For the most academic route post-16, A levels, there were substantial ethnic differences, with minority ethnic groups generally being more likely to state a desire to follow this path. Statistically significant differences were found between white UK and Asian pupils (Bangladeshis, Asian Indians and Pakistanis). Eligibility for free school meals also impacted, negatively, on aspirations. Socio-psychological variables were also shown to be of importance, particularly selfesteem and psychological distress. Depressive symptoms seemed to be less salient. Importantly, educational aspirations had a strong association with actual achievement at age 16, remaining associated even after controlling for a number of other variables, including prior achievement.

The findings here were broadly in line with the limited amount of research that has been done on variation in aspirations by ethnicity in the UK. Penn and Scattergood (1992) also found that Asian pupils were more likely to remain in education beyond compulsory leaving age. Addams and Johnson (2005) found that the lowest levels of aspiration were amongst white pupils. Strand and Winston (2008) also found variation by ethnicity, with black African and Pakistani pupils having significantly higher aspirations than the White British group. There was also evidence for the "Asian other" 
group, which included Indian pupils, having higher aspirations than the white group in their study.

A convincing argument for why educational aspirations are higher amongst minority ethnic groups than white UK youth is outlined in Strand and Winston's (2008) paper. They cite MacLeod's work on the aspirations amongst black and white youth in the United States (MacLeod 1995). MacLeod carried out research on two groups of teenagers in a high school, the "Hallway Hangers" and the "Brothers". The lowest aspirations were found amongst white teenagers who came from families who had been in the neighbourhood for the longest period of time. Amongst the black teenagers and their parents, who were more recent arrivals in the neighbourhood, there was a sense of hope. White parents tended to see fostering high aspirations amongst their children as unrealistic. The predominantly white "Hallway Hangers" made less effort at school than the mainly black "Brothers" who were less conscious of social class inequalities. The study suggests that those groups that have been in a deprived area for longest are least likely to foster attitudes which might result in "escaping" from it. This might be one reason why our paper demonstrates such high aspirations amongst Asian groups. However, in the context of the UK, where we have experienced somewhat different patterns of migration, there may well be different patterns and processes at work.

Length of time spent in a neighbourhood is also likely to be associated with migration status; children of immigrants are likely to come from families who are more recent arrivals in neighbourhoods than the white majority. It has been argued that being a migrant in itself may lead to higher educational aspirations, as many have been positively selected for their drive and ambition (Heath et al. 2008). There is some evidence that migrant parents have higher aspirations for their children, and that migration may be part of a wider social mobility drive for the family; this is known as the family mobilisation thesis (van Zanten 1997). As Heath et al. (2008) point out, these parental aspirations then have to be transmitted to the children; it has been suggested that in the Asian case in Britain, a high level of parental authority backed up by the extended family and community may be effective in doing this (Modood 2004).

Psychological distress was associated with lower educational aspirations and there was also weak evidence for an association between depressive symptoms and educational aspirations. Better self-esteem was associated with higher odds of aspiring to remain in post-compulsory education. It is possible that depressive symptoms and low self-esteem have a direct effect on aspirations by lowering expectations. Psychological distress more generally may affect functioning within the classroom which in turn impacts on educational aspirations (the SDQ, which is used to measure psychological difficulties in this sample, focuses on conduct problems, hyperactivity and peer problems as well as emotional difficulties). The strong association of psychological distress with aspirations may have implications for the lifecourse. Other research has shown that psychological disorder in childhood has an impact on eventual social position (Stansfeld et al. 2010). It may be that the role of psychological distress in lowering aspirations explains some of this link. It is of interest that whilst psychological difficulties in general appear to impact negatively on achievement, depressive symptoms specifically do not. This supports the findings of a previous study using this cohort (Rothon et al. 2009). It may be that conduct problems and hyperactivity are more salient in predicting academic achievement than emotional difficulties. 
As far as the authors are aware, no previous British study has been able to look at the impact of educational aspirations on actual achievement. Although it is interesting to look at variation in aspirations in itself, the ability to look at their impact on a measurable outcome gives far greater scope in terms of policy implications. The study itself is unusual in its focus on a particularly ethnically diverse area of Britain; this made it possible to examine in detail variation by ethnic group as there were large enough numbers in most ethnic groups to do so. These findings are specific to an inner city area and may not be generalisable to the population at large. In particular, the composition of the white British group is not representative of the white British population more generally.

The strong association between educational aspirations and actual achievement is an extremely important finding. This association holds even when prior achievement has been taken into account. This suggests that fostering high educational aspirations amongst young people may be an important means of raising achievement amongst low achieving groups, since having high aspirations in itself appears to increase the likelihood of high achievement. However, although high aspirations may result in success, it is also important to recognise that not all goals are fulfilled. There is evidence to suggest that minority ethnic students and students from lower social class backgrounds are less successful in converting high aspirations into high achievements (Alexander et al. 1994; Kilgore 1991). A variety of mechanisms may prevent ambitions from being translated into final outcomes, even when aspirations are strongly held. These include perceived or actual discrimination (Ogbu 1978, 1997) and a lack of knowledge on the functioning of the educational system (Kilgore 1991). The results of one study suggest that parents and children from lower social class backgrounds are less attuned to feedback from schools on performance, and therefore find it harder to "achieve success through self-regulating behaviour" (Alexander et al. 1994). As well as fostering high ambitions, it is important to bear in mind the constraints operating on young people as they make educational decisions and to provide them with appropriate support and guidance on achievable expectations. Alexander and colleagues suggest that parent involvement initiatives and home-school partnerships may enable parents to support their children more effectively in this respect.

The findings here have potentially important policy implications. Further research and evaluation work needs to be carried out regarding interventions. Our evidence supports conclusions reached in the recent report of the Panel on Fair Access to the Professions. We must find ways of "unleashing aspirations" and providing all children with a fair chance to succeed. The report looks at how new schools could be opened in poorer areas, how apprenticeships could be developed and how mentoring programmes can be extended to raise aspirations (Milburn 2009). Nevertheless, the report avoids addressing full-on a number of underlying problems: continuing poverty and growing inequalities in wealth and power. Our findings underline the debilitating and constraining effects of family poverty on the aspirations and educational achievement of adolescents.

Acknowledgments RELACHS was commissioned by the East London and City Health Authority. The data collection was funded by East London and City Health Authority and the Department of Health. CR is funded by a Medical Research Council Special Training Fellowship (G0601707). We would like to 
thank the adolescents who took part in the RELACHS study as well as the research team for the collection of the data.

Open Access This article is distributed under the terms of the Creative Commons Attribution Noncommercial License which permits any noncommercial use, distribution, and reproduction in any medium, provided the original author(s) and source are credited.

\section{References}

Addams, H., \& Johnson, M. (2005). London challenge: Surveys of pupils and teachers 2004. London: Department for Education and Skills.

Alexander, K., Entwisle, D., \& Bedinger, S. (1994). When expectations work: Race and socioeconomic differences in school performance. Social Psychology Quarterly, 57, 283-299.

Angold, A., Costello, E., Messer, C., Pickles, A., Winder, F., \& Silver, D. (1995). Development of a short questionnaire for use in epidemiological studies of depression in children and adolescents. International Journal of Methods in Psychiatric Research, 5, 237-249.

Angold, A., Weissman, M., Merikangas, K., Prusoff, B., Wickramaratne, P., \& Gammon, D., et al. (1987). Parent and child reports of depressive symptoms in children at low and high risk of depression. Journal of Child Psychology and Psychiatry, 28, 901-915.

Ball, S., Maguire, M., \& Macrae, S. (2000). Choice, pathways and transitions post-16. London: RoutledgeFalmer.

Bandura, A. (1978). The self-esteem in reciprocal determinism. American Psychologist, 33, 344-358.

Blau, P., \& Duncan, O. (1967). The American occupational structure. New York: Wiley.

Blumer, H. (1937). Social psychology. In E. Schmidt (Ed.), Man and society (pp. 144-198). New York: Prentice-Hall.

Breen, R., \& Goldthorpe, J. (1997). Explaining educational differentials: towards a formal rational action theory. Rationality and Society, 9, 275-305.

Brookover, W., Erickson, E., \& Joiner, L. (1967). Educational aspirations and educational plans in relation to academic achievement and socioeconomic status. The School Review, 75, 392-400.

Cheng, S., \& Starks, B. (2002). Racial differences in the effects of significant others on students' educational expectations. Sociology of Education, 75, 306-327.

Connolly, P. (2006). The effects of social class and ethnicity on gender differences in GCSE attainment: a secondary analysis of the Youth Cohort Study of England and Wales 1997-2001. British Educational Research Journal, 32, 3-21.

Croll, P. (2008). Occupational choice, socio-economic status and educational attainment: a study of the occupational choices and destinations of young people in the British Household Panel Survey. Research Papers in Education, 23, 243-268.

Demack, S., Drew, D., \& Grimsley, M. (2000). Minding the gap: Ethnic, gender and social class differences in attainment at 16, 1988-1995. Race, Ethnicity and Education, 3, 117-143.

Department for Education and Skills. (2006). Trends in education and skills.

Garg, R., Kauppi, C., Lewko, J., \& Urajnik, D. (2002). A structural model of educational aspirations. Journal of Career Development, 29, 89-108.

Ginzberg, E., Ginsberg, S., Axelrad, S., \& Herma, J. (1951). Occupational choice. New York: Colombia University Press.

Goldthorpe, J. (2000). On sociology. Oxford: Oxford University Press.

Goodman, R. (1997). The strengths and difficulties questionnaire: a research note. Journal of Child Psychology and Psychiatry and Allied Disciplines, 38, 581-586.

Goyette, K., \& Xie, Y. (1999). Educational expectations of Asian American youths: Determinants and ethnic differences. Sociology of Education, 72, 22-36.

Heath, A., Rothon, C., \& Kilpi, E. (2008). The second generation in Western Europe: education, unemployment and occupational attainment. Annual Review of Sociology, 34, 211-235.

Kao, G., \& Tienda, M. (1998). Educational aspirations and minority youth. American Journal of Education, 106, 349-384.

Kilgore, S. (1991). The organizational context of tracking in schools. American Sociological Review, 56, 189-203. 
Leavey, G., Hollins, K., King, M., Barnes, J., Papadopoulos, C., \& Grayson, K. (2004). Psychological disorder amongst refugee and migrant schoolchildren in London. Social Psychiatry and Psychiatric Epidemiology, 39, 191-195.

Leslie, D., \& Drinkwater, S. (1999). Staying on in full-time education: reasons for higher participation rates among ethnic minority males and females. Economica, 66, 77.

MacLeod, J. (1995). Ain't No Makin' It: aspirations and attainment in a low-income neighborhood. Boulder, CO: Westview Press.

Manski, C. (1993). Adolescent econometricians: how do youth infer the returns to schooling? In C. Clotfelter \& M. Rothschild (Eds.), Studies of supply and demand in higher education (pp. 43-57). Chicago: University of Chicago Press.

Marjoribanks, K. (2002). Family contexts, individual characteristics, proximal settings and adolescents' aspirations. Psychology Reports, 91, 769-779.

Mau, W., \& Bikos, L. (2000). Educational and vocational aspirations of ethnic minority female students: a longitudinal study. Journal of Counselling and Development, 78, 186-194.

Mead, G. H. (1934). Mind, self and society. Chicago: University of Chicago Press.

Meltzer, H., Gatward, R., Goodman, R., \& Ford, T. (2003). Mental health of children and adolescents in Great Britain. International Review of Psychiatry, 15, 185-187.

Milburn, A.C. (2009). Unleashing aspiration: the final report of the panel on fair access to the professions. London: Cabinet Office.

Modood, T. (2004). Capitals, ethnic identity and educational qualifications. Cultural Trends, 13, 87-105.

Mullick, M., \& Goodman, R. (2001). Questionnaire screening for mental health problems in Bangladeshi children: a preliminary study. Social Psychiatry Psychiatric Epidemiology, 36, 94-99.

Muris, P., Meesters, C., \& Vanden Bergh, F. (2003). The Strengths and Difficulties Questionnaire (SDQ): further evidence for its reliability and validity in a community sample of Dutch children. European Child and Adolescent Psychiatry, 12, 1-8.

Ogbu, J. (1978). Minority education and caste. New York: Academic Press.

Ogbu, J. (1997). Racial stratification and education in the United States: why inequality persists. In A. Halsey, H. Lauder, P. Brown, \& A. Stuart Wells (Eds.), Education: Culture, economy, society (pp. 765778). Oxford: Oxford University Press.

Penn, R., \& Scattergood, H. (1992). Ethnicity and career aspirations in contemporary Britain. New Community, 19, 75-98.

Rosenberg, M. (1965). Society and the adolescent self-image. Princeton: Princeton University Press.

Rothon, C. (2007). Can achievement differentials be explained by social class alone? An examination of minority ethnic educational performance in England and Wales at the end of compulsory education. Ethnicities, 7, 306-322.

Rothon, C. (2008). Women, men and social class revisited: an assessment of the utility of a 'combined' schema in the context of minority ethnic educational achievement in Britain. Sociology, 42, 691-708.

Rothon, C., Head, J., Clark, C., Klineberg, E., Cattell, V., \& Stansfeld, S. (2009). The impact of psychological distress on the educational achievement of adolescents at the end of compulsory education. Social Psychiatry and Psychiatric Epidemiology, 44, 421-427.

Sewell, W., \& Hauser, R. (1980). The Wisconsin longitudinal study of social and psychological factors in aspirations and achievements. Research in Sociology of Education and Socialization, 1, 59-99.

Sewell W., \& Hauser R. (1993). A review of the Wisconsin longitudinal study of social and psychological factors in aspirations and achievements 1963-1992. Ref Type: Unpublished work.

Sewell, W., Hauser, R., \& Wolf, W. (1980). Sex, schooling and occupational status. American Journal of Sociology, 86, 551-583.

Sewell, W., \& Shah, V. (1967). Socioeconomic status, intelligence and the attainment of higher education. Sociology of Education, 40, 1-23.

Sewell, W., \& Shah, V. (1968). Social class, parental encouragement and educational aspirations. American Journal of Sociology, 73, 559-572.

Stansfeld, S., Clark, C., Rodgers, B., Caldwell, T., \& Power, C. (2010). Repeated exposure to socioeconomic disadvantage and health selection as life course pathways to mid-life depressive and anxiety disorders. Social Psychiatry and Psychiatric Epidemiology (epub ahead of print).

Stansfeld, S., Haines, M., Booy, R., Taylor, S., Viner, R., \& Head, J., et al. (2003). Health of young people in East London: The RELACHS Study 2001. London: The Stationary Office.

Strand, S., \& Winston, J. (2008). Educational aspirations in inner city schools. Educational Studies, 34, 249-267. 
Super, D. (1953). A theory of vocational development. American Psychologist, 8, 185-190.

Super, D. (1969). Vocational development theory: Persons, positions and processes. The Counseling Psychologist, 1, 2-9.

Super, D. (1980). A life-span, life-space approach to career development. Journal of Vocational Behavior, 16, 282-298.

Teachman, J. (1987). Family backgrond, educational resources and educational attainment. American Sociological Review, 52, 548-557.

Teachman, J., \& Paasch, K. (1998). The family and educational aspirations. Journal of Marriage and the Family, 60, 704-714.

van Zanten, A. (1997). Schooling immigrants in France in the 1990s: success or failure of the Republican model of integration. Anthropology and Education Quarterly, 28, 351-374.

Williams, T. (1972). Educational aspirations: longitudinal evidence on their development in Canadian youth. Sociology of Education, 45, 107-133.

Zimet, G., Dahlem, N., Zimet, S., \& Farley, G. (1988). The multidimensional scale of perceived social support. Journal of Personality Assessment, 52, 30-41.

\section{Author Biographies}

Catherine Rothon is a Medical Research Council Special Training Fellow at the Centre for Psychiatry, Wolfson Institute of Preventive Medicine, Barts and the London School of Medicine and Dentistry, Queen Mary University of London. Her research interests include the links between mental health and academic performance, ethnic inequalities in educational achievement and the ways in which "social capital" might influence health and educational outcomes.

Muna Arephin is a Ph.D. student at the Centre for Epidemiology, Mathematics and Statistics, Wolfson Institute of Preventive Medicine, Barts and the London School of Medicine and Dentistry, Queen Mary University of London. Her research interests concern the design and analysis of multi-arm clinical trials.

Emily Klineberg is a Research Associate at the Department of Social Medicine, University of Bristol. Her research interests are adolescent mental health, self-harm and suicidal behaviour.

Vicky Cattell, a sociologist, is an Honorary Senior Lecturer at the Centre for Psychiatry, Wolfson Institute for Preventive Medicine, Barts and the London School of Medicine and Dentistry, Queen Mary University of London. Her research interests include: community life in low income neighbourhoods, residents' social networks and their implications for well being.

Stephen Stansfeld is Professor of Psychiatry and Lead of the Centre for Psychiatry, Wolfson Institute of Preventive Medicine, Barts and the London School of Medicine and Dentistry, Queen Mary University of London. His research interests include the effects of the physical and social environment on mental health and childhood predictors of adult mental health. He also works as an honorary consultant psychiatrist in psychiatric rehabilitation. 